\title{
Front Matter: Volume 7656
}

, "Front Matter: Volume 7656," Proc. SPIE 7656, 5th International Symposium on Advanced Optical Manufacturing and Testing Technologies: Optical Test and Measurement Technology and Equipment, 765601 (21 October 2010); doi: $10.1117 / 12.866263$

SPIE Event: 5th International Symposium on Advanced Optical Manufacturing and Testing Technologies, 2010, Dalian, China 


\title{
PROCEEDINGS OF SPIE
}

\section{5th International Symposium on Advanced Optical Manufacturing and Testing Technologies Optical Test and Measurement Technology and Equipment}

\author{
Yudong Zhang \\ Jose M. Sasian \\ Libin Xiang \\ Sandy To \\ Editors
}

26-29 April 2010

Dalian, China

Sponsored by

COS-The Chinese Optical Society (China) • IOE-The Institute of Optics and Electronics, CAS (China)

Cosponsored by

SPIE

Supporting Organizations

Ministry of Science and Technology of China (China) • Chinese Academy of Sciences (China)

National Natural Science Foundation of China (China)

Cooperating Organizations

Fraunhofer Institute for Applied Optics and Precision Engineering (Germany) • Singapore Institute of Optics and

Photonics (Singapore) • Optical Society of Sichuan Province (China) • State Key Laboratory of Microfabrication

(China) - Dalian Institute of Chemical Physics, CAS (China) - Dalian University of Technology (China) • Changchun

Institute of Optics, Fine Mechanics and Physics, CAS (China) • Changchun University of Technology (China) • National

University of Defense Technology (China) • University of Electronic Science and Technology of China (China) • Harbin

Institute of Technology (China) • Beijing Institute of Technology (China) • Crystechcoating Inc. (China)

Published by

SPIE

Part One of Three Parts

Volume 7656

Proceedings of SPIE, 0277-786X, v. 7656

SPIE is an international society advancing an interdisciplinary approach to the science and application of light. 
The papers included in this volume were part of the technical conference cited on the cover and title page. Papers were selected and subject to review by the editors and conference program committee. Some conference presentations may not be available for publication. The papers published in these proceedings reflect the work and thoughts of the authors and are published herein as submitted. The publisher is not responsible for the validity of the information or for any outcomes resulting from reliance thereon.

Please use the following format to cite material from this book:

Author(s), "Title of Paper," in 5th International Symposium on Advanced Optical Manufacturing and Testing Technologies: Optical Test and Measurement Technology and Equipment, edited by Yudong Zhang, Jose Sasian, Libin Xiang, Sandy To, Proceedings of SPIE Vol. 7656 (SPIE, Bellingham, WA, 2010) Article CID Number.

ISSN 0277-786X

ISBN 9780819480866

Published by

SPIE

P.O. Box 10, Bellingham, Washington 98227-0010 USA

Telephone +1 3606763290 (Pacific Time) · Fax +1 3606471445

SPIE.org

Copyright () 2010, Society of Photo-Optical Instrumentation Engineers

Copying of material in this book for internal or personal use, or for the internal or personal use of specific clients, beyond the fair use provisions granted by the U.S. Copyright Law is authorized by SPIE subject to payment of copying fees. The Transactional Reporting Service base fee for this volume is $\$ 18.00$ per article (or portion thereof), which should be paid directly to the Copyright Clearance Center (CCC), 222 Rosewood Drive, Danvers, MA 01923. Payment may also be made electronically through CCC Online at copyright.com. Other copying for republication, resale, advertising or promotion, or any form of systematic or multiple reproduction of any material in this book is prohibited except with permission in writing from the publisher. The CCC fee code is 0277-786X/10/\$18.00.

Printed in the United States of America.

Publication of record for individual papers is online in the SPIE Digital Library.

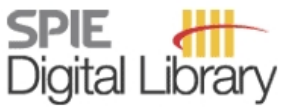

SPIEDigitalLibrary.org

Paper Numbering: Proceedings of SPIE follow an e-First publication model, with papers published first online and then in print and on CD-ROM. Papers are published as they are submitted and meet publication criteria. A unique, consistent, permanent citation identifier (CID) number is assigned to each article at the time of the first publication. Utilization of CIDs allows articles to be fully citable as soon they are published online, and connects the same identifier to all online, print, and electronic versions of the publication. SPIE uses a six-digit CID article numbering system in which:

- The first four digits correspond to the SPIE volume number.

- The last two digits indicate publication order within the volume using a Base 36 numbering system employing both numerals and letters. These two-number sets start with $00,01,02,03,04$, $05,06,07,08,09,0 A, 0 B \ldots 0 Z$, followed by 10-1Z, 20-2Z, etc.

The CID number appears on each page of the manuscript. The complete citation is used on the first page, and an abbreviated version on subsequent pages. Numbers in the index correspond to the last two digits of the six-digit CID number. 


\title{
Contents
}

\section{Part One}

\author{
xxvii Symposium Committees \\ xxix Conference Committee \\ xxxi Introduction
}

\section{SESSION 3-1}

765602 Phase retrieval in situ measurement for large aperture parabolic mirror [7656-01]

L. Ding, Y. WU, S. Li, Y. Liao, Y. Shu, National Univ. of Defense Technology (China)

765603 Subaperture stitching based on Hartmann wavefront sensor [7656-02]

Y. He, Institute of Optics and Electronics (China) and Graduate School of Chinese Academy of Sciences (China); G. Tang, Institute of Optics and Electronics (China)

765604 Optimizing operating parameters of spectrophotometer for testing transmission spectrum of optical substrate [7656-03]

H. Liu, Tongji Univ. (China) and Tianjin Key Lab. of Optical Thin Film (China); D. Liu, Tianjin Key Lab. of Optical Thin Film (China); Y. Ji, Tianjin Key Lab. of Optical Thin Film (China) and Harbin Institute of Technology (China); Z. Wang, Tongji Univ. (China); D. Chen, Harbin Institute of Technology (China); Z. Shen, B. Ma, Tongji Univ. (China); W. Zhang, Tianjin Key Lab. of Optical Thin Film (China); M. Liu, Military Representatives Bureau of NED, Tianjin (China); Z. Wu, R. Wang, Tianjin Key Lab. of Optical Thin Film (China)

765605 Fiber Bragg grating demodulatin system based on ARM and LabVIEW [7656-04]

Y. Zhang, C. Wu, Y. Qiu, Yanshan Univ. (China)

765606 Design of null tests for an $F / 0.8$ concave oblate elliptical surface [7656-05]

X. Ding, B. Yang, C. Liu, X. Wang, Y. Liu, Shanghai Institute of Technical Physics (China)

765607 Phase modulating two Fabry-Perot interferometry and its application to nanometrology [7656-06]

B. Gou, China Jiliang Univ. (China); L. Zhu, Zhejiang Univ. (China); J. Miao, Y. Huang, T. Wei,

R. Zhu, China Jiliang Univ. (China)

765608 Study of ocean red tide multi-parameter monitoring technology based on double-wavelength airborne lidar system [7656-07]

H. Lin, X. Wang, Xiao Gan Univ. (China); K. Liang, Hua Zhong Univ. of Science and Technology (China)

765609 Application of wavelet analysis in laser Doppler vibration signal denoising [7656-08] Y. Lan, H. Xue, Northwestern Polytechnical Univ. (China); X. Li, AVIC Changcheng Institute of Metrology and Measurement (China); D. Liu, Northwestern Polytechnical Univ. (China)

7656 OA Super-smooth surface defects measurement and evaluation system [7656-09]

X. Gao, Y. Yang, P. Zhao, B. Xiao, Zhejiang Univ. (China) 
$7656 \mathrm{OB} \quad$ Kossel diffraction and conformation investigation of colloidal crystals [7656-10] H. Yang, C. Wang, Z. Sun, S. Cao, G. Zhai, Ctr. for Space Science and Applied Research (China); M. Li, Institute of Physics (China)

7656 OC Practical testing device for fluorescence lifetime on $\mu$ sith LCD display [7656-1 1] J. Li, G. Zhai, B. Wang, F. Yang, F. Jin, R. Chen, L. Ma, Southwest Institute of Technical Physics (China)

\section{SESSION 3-2}

7656 OD Study and considerations of nanometer and nano-radian surface profiler [7656-12] S. Qian, K. Qian, Brookhaven National Lab. (United States)

$7656 \mathrm{OE} \quad$ Eliminating noises contained in sensing signals from a self-mixing laser diode [7656-13] Y. Yu, Univ. of Wollongong (Australia); T. Mei, Shenyang Ligong Univ. (China); J. Xi, J. F. Chicharo, Univ. of Wollongong (Australia); H. Ye, Zhengzhou Univ. (China); Z. Wang, Xian Jiaotong Univ. (China)

7656 OF Polarization point-diffraction interferometer for high-precision testing of spherical surface [7656-14]

D. Wang, Y. Yang, C. Chen, Y. Zhuo, Zhejiang Univ. (China)

7656 OG Novel metrological tuning fork atomic force microscope for optical surface characterization [7656-15]

J. Zhao, T. Guo, L. Ma, X. Fu, X. Hu, Tianjin Univ. (China)

$7656 \mathrm{OH}$ Identification and quantification of non-commonpath error in lateral shearing interferometry [7656-16]

B. Liu, A. Tian, H. Wang, C. Wang, Xi'an Technological Univ. (China)

7656 Ol Study on the transverse chromatic aberration of the individual eye model after LASIK refractive surgery [7656-17]

M. Zhang, Z. Wang, Nankai Univ. (China); Y. Wang, T. Zuo, Tianjin Eye Hospital (China)

$76560 \mathrm{~J} \quad$ Test of visible spectral transmittance of large aperture optical lens [7656-18]

J. Wang, S. Chen, National Univ, of Defense Technology (China); X. Wu, The 613th Research Institute of China Aviation Industry (China); Y. WU, C. Guan, National Univ, of Defense Technology (China)

7656 OK Nondestructive measuring soluble solid contents and weight of intact pears based on on-line near-infrared spectroscopy [7656-19]

Y. Pan, X. Sun, East China Jiaotong Univ. (China); X. Dong, Jiangxi Normal Univ. (China);

Y. Hao, Y. Liu, East China Jiaotong Univ. (China)

$7656 \mathrm{OL}$ Overview on the profile measurement of turbine blade and its development [7656-20] J. Huang, Z. Wang, J. Gao, Xi'an Jiaotong Univ. (China); Y. Yu, Univ. of Wollongong (Australia)

7656 OM Performance of mode-biased wavefront sensor to detect multiple aberration modes [7656-21]

C. Liu, Z. Jiang, S. Huang, H. Ma, F. Xi, National Univ. of Defense Technology (China) 
$7656 \mathrm{ON} \quad$ Error analysis and system optimization of non-null aspheric testing system [7656-22]

Y. Luo, Y. Yang, D. Liu, C. Tian, Y. Zhuo, Zhejiang Univ. (China)

$765600 \quad$ Error analysis of spherical ultra-precision measurement [7656-23]

D. Wang, K. Wang, Y. Shen, J. Peng, Zhejiang Univ. (China)

7656 OP Hybrid phase retrieval algorithm for solving the twin image problem in in-line digital holography [7656-24]

J. Zhao, D. Wang, Beijing Univ. of Technology (China); F. Zhang, Univ. of Sheffield (United Kingdom); Y. Wang, Beijing Univ. of Technology (China)

$76560 Q$ Some novel combining approaches to reduce speckle noises [7656-25]

X. Yang, Z. Fan, J. Gui, Y. Lou, Kunming Univ. of Science and Technology (China)

7656 OR Automatic procedure for non-coplanar aberration compensation in lensless Fourier transform digital holography [7656-26]

H. Cui, D. Wang, Y. Wang, C. Liu, J. Zhao, Y. Li, Beijing Univ. of Technology (China)

\section{SESSION 3-3}

7656 OS Certification, self-calibration, and uncertainty in testing optical flats [7656-27]

C. J. Evans, Zygo Corp. (United States)

7656 OT Research on time-resolved terahertz spectroscopy [7656-28]

Y. Deng, Q. Sun, National Institute of Metrology (China); F. Liu, C. Wang, Q. Xing, Tianjin Univ. (China)

7656 OU Determining the profile parameters of photoresist grating with spectrum deductive method [7656-29]

X. Chen, C. Li, J. Wu, Z. Hu, Soochow Univ. (China)

7656 OV Performance comparison of optical path difference calculation algorithms for wavelength scanning interferometry [7656-30]

K. W. Wang, C. Long, Zhejiang Univ. (China)

7656 OW Study of optimum pumping intensity at Cs vapor magnetometer [7656-31]

J. Zhang, Harbin Engineering Univ. (China); F. Wang, Harbin Engineering Univ. (China) and Heilongjiang Institute of Science and Technology (China); J. Li, W. Sun, Harbin Engineering Univ. (China)

7656 OX Surface roughness measurement by digital holography [7656-32]

Y. Li, D. Wang, J. Zhao, Beijing Univ. of Technology (China); G. Wang, Beijing Univ. of Technology (China) and Henan Institute of Metrology (China); Y. Wang, Beijing Univ. of Technology (China)

7656 OY Application of the laser scanning confocal microscope in fluorescent film sensor research [7656-33]

H.-Y. Zhang, W.-M. Liu, W.-W. Zhao, Q. Dai, P.-F. Wang, Technical Institute of Physics and Chemistry (China) 
$76560 Z$ Dynamic closed-loop test for real-time drift angle adjustment of space camera on the Earth [7656-34]

J. Hu, X. Cao, D. Wang, W. Wu, S. Xu, Changchun Institute of Optics, Fine Mechanics and Physics (China)

765610 Investigation of a laser frequency stabilization method based on linear magneto-optics effect [7656-35]

X. Zeng, J. Zhang, Harbin Engineering Univ. (China); Q. Liu, Harbin Engineering Univ. (China) and Daqing Petroleum Institute (China); Z. Huang, J. Zhang, W. Sun, Harbin Engineering Univ. (China)

765611 Effects of mechanical inaccuracies on the measurement result in metrology systems [7656-36] F. Schneider, Univ. of Applied Sciences Deggendorf (Germany) and Univ. of the West of England (United Kingdom); M. Schinhaerl, C. Vogt, R. Maurer, P. Sperber, R. Rascher, Univ. of Applied Sciences Deggendorf (Germany); R. Stamp, G. Smith, Univ. of the West of England (United Kingdom)

765612 Study on phase retrieval of a single closed fringe interferogram in radial shearing interferometer for aspheric test [7656-37]

C. Tian, Y. Yang, Y. Luo, D. Liu, Y. Zhuo, Zhejiang Univ. (China)

765613 Development and innovation on integrated engineering optics system design [7656-38] Q. Ding, H. Liu, National Key Lab. of Science and Technology on Fire Control (China); L. Zhou, Beijing Institute of Technology (China)

765614 Uniform illumination for large area digital speckle pattern interferometry using multibeam [7656-39]

Z. Huang, M. Zhu, H. Cai, Y. Zhang, Tianjin Univ. (China)

765615 Zernike polymomials for rectangular area and applications in off-axis asphere testing [7656-40]

P. He, X. Zong, R. Fu, Beijing Institute of Space Mechanics and Electronics (China)

765616 Apparatus for femtosecond laser measurement [7656-41]

Q. Sun, Y. Deng, S. Cao, J. Yu, National Institute of Metrology (China); Q. Wang, Univ. of Tianjin (China); Z. Zhang, Peking Univ. (China)

\section{POSTER SESSION}

765617 Detection of infrared dim targets based on crossover matching evolution operator [7656-42] H. Y. Zhang, X. Wen, Xiamen Univ. (China)

765618 Research on Doppler frequency in incoherent FM/CW laser detection [7656-43]

K. Liu, Z. Cui, Beijing Institute of Technology (China)

765619 Measurement of the Muller matrix for painted surfaces with a kind of scatterometer [7656-44] W. Feng, Yantai Institute of Coastal Zone Research for Sustainable Development (China); Q. Wei, Anhui Institute of Optics and Fine Mechanics (China); L. Chen, Yantai Institute of Coastal Zone Research for Sustainable Development (China) 
7656 1 A Study on vertical bright line image of CCD camera irradiated by laser [7656-45] T. Jiang, Z. Zhang, X. Cheng, National Univ. of Defense Technology (China)

7656 1B Wall-drag effect of dense Brownian particles close to solid-liquid interface in low-coherence dynamic light scattering [7656-46]

H. Xia, F. Li, Z. Chen, Q. Li, Y. Xiao, K. Lv, Central South Univ. (China)

7656 1C Novel optical fiber sensor for deformation measurement [7656-47]

H. Di, Northeast Forestry Univ. (China); S. Sun, Harbin Univ. of Science and Technology

(China); J. Yu, Northeast Forestry Univ. (China); R. Liu, Shanghai Jiao Tong Univ. (China)

7656 1D Multiple location analysis method for the detection of point targets [7656-48]

X. Wen, H.-Y. Zhang, Xiamen Univ. (China)

7656 IE Image detection of pantograph slide basedoOn yang-shot mode [7656-49]

P. Shi, L. Wang, X. Gao, K. Yang, W. Zhou, Southwest Jiaotong Univ. (China)

7656 IF Simultaneous determination of benzo[k]fluoranthene and perylene using excitation-emission matrix fluorescence [7656-50]

H.-B. Wang, Y.-J. Zhang, J.-B. Duan, X. Xiao, S.-H. YU, K. Zhang, Anhui Institute of Optics and Fine Mechanics (China)

7656 IG Intensity-modulated and temperature-insensitive fiber Bragg grating vibration sensor [7656-51]

L. Li, X. Dong, S. Zhang, C. Zhao, Y. Sun, China Jiliang Univ. (China)

$7656 \mathrm{1H}$ Reconstruction algorithm realization with FPGA based on the emission spectral tomography [7656-52]

B. Leng, X. Wan, Z. Zhang, X. Deng, N. Luo, Nanchang Hangkong Univ. (China)

$765611 \quad$ Evaluation of kinetic constants of biomolecular interaction on optical surface plasmon resonance sensor with Newton Iteration Method [7656-53]

Y. Zhao, G. Jiang, J. Hu, F. Hu, J. Wei, L. Shi, Henan Agricultural Univ. (China)

7656 iJ Monitoring system of multiple fire fighting based on computer vision [7656-54]

J. Li, L. Wang, X. Gao, Z. Wang, Q. Zhao, Southwest Jiaotong Univ. (China)

7656 1K Quantitative analyses of tartaric acid based on terahertz time domain spectroscopy

[7656-55]

B. Cao, M. Fan, China Univ. of Mining and Technology (China)

$76561 \mathrm{~L}$ Research on the detection system of liquid concentration base on birefringence light transmission method [7656-56]

T. Li, X. Zhang, L. Hou, C. Jiang, Shandong Univ. of Technology (China)

7656 1M Moire Ct technique and its application on laser flexible manufacture [7656-57]

T. Li, L. Hou, C. Jiang, X. Zhang, Shandong Univ. of Technology (China) 
7656 iN New method to improve measurement accuracy of modulation transfer function [7656-58] Z. Song, Xi'an Institute of Optics and Precision Mechanics (China) and Graduate School of the Chinese Academy of Sciences (China); W. Gao, Xi'an Institute of Optics and Precision Mechanics (China); Y. Zhou, Xi'an Jiaotong Univ. (China); F. Liu, Xi'an Institute of Optics and Precision Mechanics (China)

765610 Research on fiber-optic gyroscope signal detection with lock-in amplifier [7656-59] X. Zhang, T. Li, X. Song, C. Jiang, L. Hou, Shandong Univ. of Technology (China)

7656 IP Measurement of refractive indices and optical axis of a uniaxial crystal assisted by Brewster angle and reflectivity fitting techniques [7656-60]

J. H. Xing, Changshu Institute of Technology (China) and Nanjing Univ. (China)

7656 1Q New method of gas concentration measurement based on continuous wave cavity ring-down [7656-61]

Q. Yang, Z. Li, J. Yan, W. Liu, Yanshan Univ. (China)

7656 IR CCD de-noising technology based on mathematical morphology [7656-62]

F. Wen, T. Li, Shandong Univ. of Technology (China)

7656 is Research of embedded fiber Bragg grating temperature sensor system [7656-63]

J. Hu, S. Wan, C. Xie, Z. Zhang, N. Luo, S. He, Nanchang Hangkong Univ. (China)

7656 IT New pseudo-random coded colored structured light technique in camera self-calibration [7656-64]

Z. XU, R. XU, Y. Wang, B. Li, K. Xiao, Jiangsu Univ. (China)

7656 IU Trinocular stereo vision method based on mesh candidates [7656-65]

B. Liu, G. XU, H. Li, Yanshan Univ. (China)

7656 IV Technology of classification on fruit defects based on infrared thermography [7656-66]

J. Zhou, Q. Zhou, J. Liu, D. XU, L. Shu, East China Jiaotong Univ. (China)

7656 1W Speed mismatch error in the profile measurement of moving object by using TDI imaging system [7656-67]

E. Hu, China Univ. of Mining and Technology (China)

7656 1X Novel method for adjusting of single star simulator using Penta prism [7656-68]

D. Su, H. Liu, W. Wang, J. Yang, National Univ. of Defense Technology (China); J. Yang, Xi'an Military Academy (China); H. Jia, National Univ. of Defense Technology (China)

7656 1Y High-accuracy two-dimensional small-angle measurement based on laser multiple-reflection [7656-69]

W. Wang, H. Liu, L. Deng, J. Tan, J. Yang, National Univ. of Defense Technology (China);

J. Yang, Xi'an Military Academy (China)

765612 Potential applications of photothermal interferometric detection technique in the single-layer optical thin film system [7656-70]

$\mathrm{H}$. Hao, Chongaing Univ. of Posts and Telecommunications (China); J. Fang, Zhejiang

Normal Univ. (China); X. Liu, Institute of Optics and Electronics (China) 
765620 Design of large-size aspheric measurement system and motion accuracy analysis [7656-71] Y. Zhu, Y. Guo, W. Luo, L. Chen, Xiamen Univ. (China)

765621 Fabrication 3D buried channel optical waveguide modulators on field-driven ion exchange process [7656-72]

Z. Zhou, W. Chen, L. Zhu, J. Li, X. Luo, Southwest Univ. of Science and Technology (China)

765622 Study of measuring the intensity distribution of LED with lock-in amplifier [7656-73]

K. Zhang, Anhui Institute of Optics and Fine Mechanics (China), State Key Lab. of Pulsed Power Laser Technology (China), and Electronic Engineering Institute of PLA (China);

Y. Zhang, G. Yin, X. Xiao, H. Wang, L. Guo, W. Liu, Anhui Institute of Optics and Fine Mechanics (China)

765623 Application of semiconductor laser on big dimension measuring system [7656-74] H. Zhang, X. Zhai, Z. QU, H. Zhang, Changchun Institute of Engineering and Technology (China)

765624 Multi-camera calibration based on openCV and multi-view registration [7656-75] X. Deng, X. Wan, Z. Zhang, B. Leng, N. Lou, S. He, Nanchang Hangkong Univ. (China)

765625 Transmission characters numerical simulation of soliton based on dispersion-managed [7656-76]

X. Lu, D. Wang, Institute of Science, Information Engineering Univ. (China)

765626 Interference of convergent polarized light to test crystal optical surface [7656-77]

C. Duan, Xi'an Technological Univ. (China); S. Zhang, Northwestern Univ. (China); X. Hu, S. Lu, Xi'an Technological Univ. (China)

765627 Analysis of the optical characteristic of particles by the discrete dipole approximation method [7656-78]

Q. Li, G. Zhang, Y. Liu, Huazhong Normal Univ. (China)

765628 Spatio-temporal characteristic of streamer discharge detected by photoelectric method [7656-79]

F. Yang, L. Jia, S. Liu, Agricultural Univ. of Hebei (China)

765629 Measurement of the geometric parameters of power contact wire based on binocular stereovision [7656-80]

X. Pan, Y. Zhang, F. Meng, Changzhou Institute of Technology (China)

7656 2A Finger-vein image separation algorithms and realization with MATLAB [7656-81]

X. Gao, J. Ma, J. Wu, Univ. of Shanghai for Science and Technology (China)

7656 2B Measurement and study of partial VOCs based on open path FTIR [7656-82] J. Tong, W. Liu, M. Gao, Z. Liu, L. Xu, X. Wei, L. Jin, Anhui Institute of Optics and Fine Mechanics (China)

7656 2C Hyperspectral reflectance imaging for detecting citrus canker based on dual-band ratio image classification method [7656-83]

J. Li, X. Rao, J. Guo, Y. Ying, Zhejiang Univ. (China) 
7656 2D Comparison of optical surface roughness measured by stylus profiler, AFM, and white light interferometer using power spectral density [7656-84]

J. Chen, T. Sun, J. Wang, Harbin Institute of Technology (China)

\section{Part Two}

$76562 \mathrm{E}$ Design and characterization of a large-area integrating sphere uniform radiation source for calibration of satellite remote sensors [7656-85]

Y. He, Beijing Institute of Technology (China); P. Li, G. Feng, Y. Wang, Z. Liu, C. Zheng, H. Wu, National Institute of Metrology (China); X. Zong, Y. Zhang, Y. Li, Beijing Institute of Space Mechanics and Electricity (China); D. Sha, Beijing Institute of Technology (China)

$76562 F \quad$ Description of a system based on the DFB laser for natural gas leakage in the long optical-path of the tunnel [7656-86]

X. Shu, Y. Zhang, W. Liu, S. Zhang, Y. Cui, R. Kan, H. Gen, Anhui Institute of Optics and Fine Mechanics (China)

$76562 \mathrm{G}$ Displacement measurement using phase joint transform correlators [7656-87]

P. Ge, Q. Li, H. Feng, Z. Xu, Zhejiang Univ. (China)

$76562 \mathrm{H}$ Step height evaluation in the vibrating condition based on microscopic interferometry [7656-88]

Y. Bian, Tianjin Univ. of Technology and Education (China); T. Guo, Tianjin Univ. (China)

$765621 \quad$ Study on method of data standardization in interferometric testing [7656-89]

W. Chen, Xi'an Univ. of Science and Technology (China)

7656 2J Absolute realization of low BRDF value [7656-90]

Z. Liu, Beijing Institute of Technology (China) and National Institute of Metrology (China); N. Liao, Beijing Institute of Technology (China); P. Li, Y. Wang, National Institute of Metrology (China)

$76562 \mathrm{~K}$ Compensation algorithm for optical flow vectors based on image sequences of the spot [7656-91]

Y. Zhao, Harbin Institute of Technology (China) and Harbin Univ. of Science and Technology (China); F. Yuan, Z. Ding, Harbin Institute of Technology (China)

$76562 \mathrm{~L} \quad$ New data reduction method with local interpolation and global fitting for complementary annular subaperture interferometry [7656-92]

X. Hou, F. WU, L. Yang, Institute of Optics and Electronics (China)

$76562 \mathrm{M}$ Nonlinearity analysis of dual-frequency laser interferometer with two longitudinal modes [7656-93]

T. Zhang, Y. WU, L. Dong, Sichuan Univ. (China)

$76562 \mathrm{~N} \quad$ Aspheric surface testing by irradiance transport equation [7656-94]

R. Shomali, Zanjan Univ. (Iran, Islamic Republic of); A. Darudi, S. Nasiri, Zanjan Univ. (Iran, Islamic Republic of) and Institute for Advanced studies in Basic Science (Iran, Islamic Republic of); A. Asgharsharghi Bonab, Zanjan Univ. (Iran, Islamic Republic of) 
765620 Study on paper moisture measurement method by monochromatic light sources [7656-95] C. Mo, X. Du, P. He, L. Zhang, N. Li, M. Wang, Harbin Univ. of Commerce (China)

7656 2P Fiber Bragg grating sensor based on an erbium-doped fiber ring laser [7656-96] H. Pang, H. Cui, Hebei Univ. of Science and Technology (China)

$76562 Q$ Self-mixing interferometry based on quadrature demodulation technique for displacement measurement [7656-97]

D. Guo, H. Hao, Nanjing Normal Univ. (China); D. Han, Nanchang Univ. (China)

$76562 R \quad$ New method for testing diffraction efficiency of AOTF [7656-98]

Y. Shen, S. Yang, Z. He, Shanghai Institute of Technical Physics (China)

765625 Modal analysis of low-level-light aiming sight-glass based on shock testing conditions [7656-99]

Y. Gao, Nanyang Institute of Technology (China) and Nanjing Univ. of Science and Technology (China); H. Ding, X. Xue, Y. XU, Nanyang Institute of Technology (China);

B. Chang, Nanjing Univ. of Science and Technology (China)

7656 2T Fabrication and test of a concave oblate ellipsoid with large relative aperture [7656-100] K. Li, Tongji Univ. (China); L. Yuan, Shanghai Institute of Technical Physics (China); P. Hao, Tongji Univ. (China)

$76562 \mathrm{U}$ Research on fiber-optic sensors for methane detection based on Harmonic detection [7656-101]

S. Wang, L. Huang, Z. Zhou, Z. Zhu, Yanshan Univ. (China)

$76562 \mathrm{~V}$ Sensitivity of PANDA high-birefringence fiber loop mirror with temperature sensing [7656-102]

L. Zhou, L. Wang, S. Hu, Beijing Univ. of Technology (China)

$76562 \mathrm{~W}$ Random-modulation CW laser ceilometer signal processing based on compound PN sequence [7656-103]

J. He, Y. Zhang, W. Liu, J. Ruan, L. Wang, Anhui Institute of Optics and Fine Mechanics (China)

$76562 \mathrm{X}$ Influence of non-ideal performance of lasers on displacement precision in single-grating heterodyne interferometry [7656-104]

G. Wang, X. Xie, S. Yan, National Univ. of Defense Technology (China)

$76562 Y$ Study on the test of transient ultraviolet spectrum for remote extended area sources with spectrometer [7656-105]

H. Li, H. Yang, B. Wu, W. Chang, Z. Bai, Xi'an Institute of Applied Optics (China); Q. Yin, Xi'an Jiaotong Univ. (China)

$76562 Z$ Design of a large area 3D surface structure measurement system [7656-106]

S. Wang, Hubei Automotive Industries Institute (China) and Huazhong Univ. of Science and Technology (China); X. Li, Y. Chen, Hubei Automotive Industries Institute (China); T. Xie,

Huazhong Univ. of Science and Technology (China) 
765630 Design of a large area 2D microscopy image measurement system [7656-107] X. Li, Y. Chen, Hubei Automotive Industries Institute (China); S. Wang, Hubei Automotive Industries Institute (China) and Huazhong Univ. of Science and Technology (China); T. Xie, Huazhong Univ. of Science and Technology (China)

765631 FBG array demodulation based on optical wavelet filtering [7656-108]

S. Qi, Z. Wu, C. Wang, Z. Kong, Northeast Univ. at Qinhuangdao (China)

765632 Study on thin film thickness measurement method based on digital image processing [7656-109]

J. Su, J. Ge, L. Yang, Xi'an Technological Univ. (China)

765633 Research on stitching interferometry aspheric surface with correcting systemic aberration [7656-110]

Y. Qiao, G. Han, Harbin Univ. of Science and Technology (China)

765634 System design of multi-function grating spectrometer [7656-111]

C. Sui, D. XU, J. Tong, Y. Yang, Zhejiang Univ. of Technology (China)

765635 Strain sensing in fatigue test of metallic material at liquid nitrogen temperature using fiber Bragg gratings [7656-112]

R. Fu, D. Zhang, J. Li, W. Li, Wuhan Univ. of Technology (China)

765636 Thermal decay characteristic of fiber Bragg gratings written into Sn doped fibers loaded hydrogen and a novel encapsulation method [7656-113]

J. Li, D. Zhang, X. Tang, W. Li, R. Fu, Wuhan Univ. of Technology (China)

765637 Linearity measurement for image-intensified CCD [7656-114]

Y. Zhao, L. Zhang, Henan Polytechnic Univ. (China); F. Yan, Y. Gu, Changchun Institute of Optics, Fine Mechanics and Physics (China); L. Wan, Dalian Univ. of Foreign Languages (China)

765638 Theoretical investigation of the bending sensing characteristics for four-core fiber Bragg grating [7656-115]

H. He, Beijing Univ. of Technology (China) and Beijing Univ. of Chemical Technology (China);

L. Wang, Beijing Univ. of Technology (China)

765639 Functional design and implementation with on-line programmable technology in optical fiber communication pulse code modulation test system [7656-116]

Y. Xu, H. Ding, Nanyang Institute of Technology (China); Y. Gao, Nanyang Institute of

Technology (China) and Nanjing Univ. of Science and Technology (China)

7656 3A Microscale linear birefringence measurement [7656-117]

Q.-L. Wu, P. Hao, S.-Y. Duan, Z.-Y. Lei, K.-Y. Wang, Univ. of Science and Technology of China (China)

7656 3B Application of ZOOM-FFT for scanning-type spectrometer based on digital signal processor [7656-118]

P. Xu, Y. Peng, Beijing Univ. of Technology (China); L. Wang, Tianjin Univ. of Technology and Education (China); H. Kang, Beijing Univ. of Technology (China) 
7656 3C Null ellipsometer with multi-wavelength [7656-119]

G. Xiao, T. Lin, T. Yang, Z. Huang, South China Normal Univ. (China)

7656 3D Novel method to examine phase object by the use of TFT-LCD [7656-120]

R. Guo, Xi'an Technological Univ. (China), Xi'an Institute of Optics and Precision Mechanics (China), and Graduate School of the Chinese Academy of Sciences (China);

B. Yao, Xi'an Institute of Optics and Precision Mechanics (China); J. Han, X. Yu, L. Nie,

C. Duan, Xi'an Technological Univ. (China); F. Wang, Beijing Institute of Technology (China)

$76563 \mathrm{E}$ Analysis of absolute testing based on even-odd functions by Zernike polynomials [7656-121] $X$. Jia, Institute of Optics and Electronics (China) and Graduate School of Chinese Academy of Sciences (China); T. Xing, W. Lin, Institute of Optics and Electronics (China)

7656 3F Research on integrating sphere low-light level stress system [7656-122]

D. Yang, D. Feng, Changchun Univ. of Science and Technology (China)

7656 3G Design research on higher precision optical fiber f-p sensor for detecting surface waves [7656-123]

S. Ning, Engineering College of The Chinese People's Armed Police Force (China); G. Heng, North China Univ. of Water Conservancy and Electric Power (China)

$76563 \mathrm{H}$ Analysis on the system error cause by lateral departure of the light source during Ronchi test [7656-124]

B. Lei, F. Wu, Institute of Optics and Electronics (China)

$765631 \quad$ Vertical scanning white light interfering profilometer based on Linnik interference microscope [7656-125]

S. Wang, Huazhong Univ. of Science and Technology (China) and Luoyang Institute of Science and Technology (China); T. Xie, S. Chang, Huazhong Univ. of Science and Technology (China)

7656 3J Research of neural network application in methane gas spectrum sensing system [7656-126] M. Zhou, H. Zhang, H. Wu, G. Yu, Anhui Univ. of Science and Technology (China)

7656 3K Analysis and test of a piezoelectric deformable mirror [7656-127]

D. Wang, C. Li, J. Wu, Suzhou Univ. (China)

7656 3L Research on fiber diameter automatic measurement based on image detection [7656-128] X. Chen, Hohai Univ. (China); Y. Jiang, OKI Communications Technology Co. (China);

W. Shen, G. Han, Hohai Univ. (China)

$76563 \mathrm{M}$ Photothermal field of multilayered spherical solids based on analogy method [7656-129]

L. Liu, Soochow Univ. (China); G. Xie, Soochow Univ. (China) and Jiangnan Univ. (China);

C. Wang, Soochow Univ. (China)

$76563 \mathrm{~N}$ Monitor the nanometer scale thickness change of optical thin film [7656-130]

Y. Yang, Z. Dai, L. Wang, K. Xiong, Xi'an Jiaotong Univ. (China) 
765630 Application of Zernike polynomials to test large aspheric surfaces in the fine grinding stage [7656-131]

Y. Deng, Wuhan Univ. of Technology (China); J. Tang, Huazhong Univ. of Science and Technology (China); F. Wu, Institute of Optics \& Electronics (China)

7656 3P Applications of high birefringent fiber in sensor and demodulation [7656-132] F. Yang, J. Zhou, Beijing Univ. of Technology (China)

$76563 Q \quad$ Measurement system for FT-IR infrared spectral emissivity of solid surface at ultra-high temperature [7656-133]

Z. Wang, J. Dai, Harerbin Institute of Technology (China); X. He, Aerospace Research Institute of Material and Processing Technology (China); C. Yang, X. Cui, Harerbin Institute of Technology (China)

$76563 R \quad$ Effects of different frequency error of mirror surface on the system imaging quality [7656-134] P. Guo, Suzhou Univ. (China); X. Wang, Northwestern Polytechnical Univ. (China)

765635 Application of thermosonics NDT in the detection of composite materials [7656-135] Y. Li, Capital Normal Univ. (China); Z. Zeng, Chongqing Normal Univ. (China); D. Chen, Beihang Univ. (China); C. Xing, N. Tao, C. Zhang, Capital Normal Univ. (China)

7656 3T Study on viscose filament electro-optical counting system based on pulse coupled neural network algorithm [7656-136]

W. Cheng, T. Zhang, X. Lin, Y. Feng, Jilin Univ. (China); W. Zhang, Wuhan Univ. (China)

$76563 \mathrm{U}$ Research on radiometric calibration of interline transfer CCD camera based on TDI working mode [7656-137]

X. Wu, J. Liu, Changchun Institute of Optics Fine Mechanics and Physics (China)

7656 3V Novel sub-pixel feature point extracting algorithm for three-dimensional measurement system with linear-structure light [7656-138]

W. Zhang, Xi'an Technological Univ. (China) and Xi'an Jiaotong Univ. (China); N. Cao, Xi'an Jiaotong Univ. (China); H. Guo, Jiyuan Power Supply Co. (China)

7656 3W New scheme of Sagnac interferometric fiber-optic current sensor insensible to mechanical vibration [7656-139]

J. Mu, Xi'an Institute of Optics and Precision Mechanics (China) and Graduate Univ. of

Chinese Academy of Sciences (China); W. Zhao, J. Wang, J. Xu, Xi'an Institute of Optics and Precision Mechanics (China)

7656 3X Raman shift of rare earth cobalt oxides [7656-140]

W. Wang, Y. Zhao, X. Han, Northeast Dianli Univ. (China)

$76563 Y \quad$ Error analysis and application of dual beam focusing method [7656-141]

Y. Guo, H. Zhao, Zhengzhou Institute of Aeronautical Industry Management (China)

765632 Application of fiber Bragg grating sensing technology in long-distance detection of temperature in weapon depots [7656-142]

J. Xu, Z. Zhang, B. Zhao, Z. Fu, Xi'an Research Institute of High Technology (China) 
765640 Fiber temperature measurement system by the demodulation of F-P filter [7656-143] D. Wang, J. Zhou, Beijing Univ. of Technology (China)

765641 Fluorescence detection system for hydrocarbon based on charge-coupled devices and complex programmable logic device [7656-144]

Z. GU, Y. Guo, Hebei Univ. of Science and Technology (China)

765642 Temperature gradients effect on surface test with high precise interferometer [7656-145] E. Miao, Changchun Institute of Optics, Fine Mechanics and Physics (China); Y. Gu, J. Zhang, Changchun Institute of Optics, Fine Mechanics and Physics (China) and Graduate School of Chinese Academy of Sciences (China); Y. Sui, H. Yang, Changchun Institute of Optics, Fine Mechanics and Physics (China)

765643 Design and fabrication of CGH for aspheric surface testing and its experimental comparison with null lens [7656-146]

F. Li, Changchun Institute of Optics, Fine Mechanics and Physics (China) and Graduate Univ. of Chinese Academy of Sciences (China); J. Zhao, R. Li, B. Zhang, L. Zheng, X. Zhang, Changchun Institute of Optics, Fine Mechanics and Physics (China)

765644 Three-dimensional reconstruction method on the PDE exhaust plume flow flame temperature field [7656-147]

Z. Zhang, X. Wan, N. Luo, S. Li, Nanchang Hang Kong Univ. (China)

765645 Research on the laboratory radiometric calibration of the thermal imager [7656-148] Z. Lu, Chang chun Institute of Optics, Fine Mechanics and Physics (China), Graduate Univ. of Chinese Academy of Sciences (China), and Northeast Normal Univ. (China); Q. Sun, J. Wang, Z. Lu, Changchun Institute of Optics, Fine Mechanics and Physics (China); Y. Liu, Northeast Normal Univ. (China)

765646 Research of FBG sensor with low frequency characteristics [7656-149]

X. Gao, P. Han, T. Liu, X. Han, Hebei Univ. of Science and Technology (China)

765647 Influence of spatial temperature distribution on high accuracy interferometric metrology [7656-150]

Y. Gu, Changchun Institute of Optics, Fine Mechanics and Physics (China) and Graduate School of Chinese Academy of Sciences (China); E. Miao, F. Yan, Changchun Institute of Optic, Fine Mechanics and Physics (China); J. Zhang, Changchun Institute of Optics, Fine Mechanics and Physics (China) and Graduate School of Chinese Academy of Sciences (China); H. Yang, Changchun Institute of Optics, Fine Mechanics and Physics (China)

765648 Novel laser beam collimation system with Hartmann-Shack wavefront sensor as a tool [7656-151]

J. Wu, J. Chen, A. XU, X. Gao, Univ. of Shanghai for Science and Technology (China)

765649 The use of image differential algorithm on multi-vision system [7656-152]

Y. Zhao, X. Qu, Tianjin Univ. (China)

7656 4A Chirp estimation of PZT for integrating-bucket method [7656-153]

J. Zhang, Changchun Institute of Optics, Fine Mechanics and Physics (China) and Graduate School of Chinese Academy of Sciences(China); Z. Shi, E. Miao, Y. Gu, W. Liu, Changchun Institute of Optics, Fine Mechanics and Physics (China) 
7656 4B New multicolor illumination system for automatic optical inspection [7656-154]

G. Xiong, Beijing Institute of Technology (China) and Beijing Technology and Business Univ. (China); S. Ma, Beijing Institute of Technology (China); X. Nie, Beijing Institute of Technology (China) and Beijing Technology and Business Univ. (China); X. Tang, Beijing Technology and Business Univ. (China)

7656 4C Study on intra-ocular lens aberration measurement in-air [7656-155]

Y. Wang, J. Chen, H. Fen, C. Hu, Y. Li, Wenzhou Medical College (China)

7656 4D Analysis and evaluation of surface characteristics of titanium coating on diamond using combined method of wavelet and fractal [7656-156]

W. Du, Harbin Institute of Technology (China) and Institute of Machinery Manufacturing Technology, China Academy of Engineering Physics (China); W. Yang, Institute of Machinery Manufacturing Technology, China Academy of Engineering Physics (China); T. Sun, Harbin Institute of Technology (China); B. Wang, Institute of Machinery Manufacturing Technology, China Academy of Engineering Physics (China)

7656 4E Design of temperature measurement system based on two-color imaging in adaptive optics of CCD [7656-157]

Y. WU, Y. Hu, F. Jiang, L. Zhang, Electronic Engineering Institute (China) and Key Lab. of Electronic Restriction (China)

7656 4F Study on the homogeneity of fused silica blanks for lithography objective [7656-158] Z. Liao, Institute of Optics and Electronics (China) and Graduate School of the Chinese Academy of Sciences (China); T. Xing, H. Zhu, Institute of Optics and Electronics (China)

7656 4G Monitoring fluorescence quenching of polycyclic aromatic hydrocarbons by humic acid in water using fluorescence fingerprints [7656-159]

X. Xiao, Y. Zhang, J. Duan, H. Wang, K. Zhang, W. Liu, Anhui Institute of Optics and Fine Mechanics (China)

$76564 \mathrm{H} \quad$ Research of laser cleaning technology for steam generator tubing [7656-160] S. Hou, J. Luo, J. Xu, B. Yuan, The Second Artillery Engineering College (China)

76564 Research of weapon equipments health monitoring based on FBG intelligent composite materials [7656-161]

Z. Zhang, Z. Fu, B. Zhao, J. Xu, The Second Artillery Engineering Institute (China)

$76564 \mathrm{~J}$ Research on aircraft trailing vortex detection based on laser's multiplex information echo [7656-162]

N. Zhao, Y. Wu, Y. Hu, W. Lei, Electronic Engineering Institute (China) and Key Lab. of Electronic Restriction (China)

7656 4K Two-beam reflectance and transmittance measurement for "Shenguang-II" facility [7656-163]

J. Miao, P. Yang, B. Zhu, J. Zhu, Shanghai Institute of Optics and Fine Mechanics (China)

$76564 \mathrm{~L} \quad$ Research on the distribution of electric field intensity and laser damage characteristics of thin films [7656-164]

Y. Li, J. Xu, J. Su, Xi'an Technological Univ. (China) 
$76564 \mathrm{M}$ Analysis on properties of PCF with elliptical rings of circular air holes [7656-165] H. Rui, L. Z. Quan, Yanshan Univ. (China)

$76564 \mathrm{~N} \quad$ Study on inner hole testing of nozzle with small size and complex contour [7656-166] L. Zhang, J. Su, L. Yang, J. Xu, Xi'an Technological Univ. (China)

765640 Coast-down time measuring system based on photoelectric method [7656-167] W. Zhu, Beijing Univ. of Technology (China) and Henan Institute of Metrology (China); D. Wang, Beijing Univ. of Technology (China); F. Qi, Henan Institute of Metrology (China)

7656 4P Study on a new method to measure objects polarization information [7656-168] S. Lu, J. Han, C. Duan, R. Guo, W. Zhang, Xi'an Technological Univ. (China)

$76564 Q \quad$ Application of DBPIP to phase errors detection in coherent beam combination [7656-169] X. Wang, Institute of Optics and Electronics (China) and The Key Lab. on Adaptive Optics (China) and Graduate School of Chinese Academy of Sciences (China); F. Shen, Institute of Optics and Electronics (China) and The Key Lab. on Adaptive Optics (China)

$76564 R \quad$ Research on far-field diffraction of cube-corner retroreflector in the satellite laser ranging system [7656-170]

Y. Weng, S. Li, H. Zhou, J. Yang, G. Zheng, P. Zhang, Wuhan Univ. (China)

7656 4S Experimental analysis of output wavefront properties for the passive Q-switched slab Nd:YAG laser [7656-171]

$X$. Zhang, Chengdu Univ. of Information Technology (China)

$76564 \mathrm{~T} \quad$ Research on the characteristics of composite light source pseudo-moxibustion medical apparatuses for digestive disease treatment [7656-172] J. Song, F. Fan, W. Hong, Yanshan Univ. (China); H. Pan, Fujian Key Lab. of Medical Instrument and Pharmaceutical Technology (China)

$76564 \mathrm{U} \quad$ Advanced fiber optic face plate quality detector design [7656-173]

Y. Liu, L. SU, J. Zhao, Harbin Engineering Univ. (China)

\section{Part Three}

7656 4V Diaphragm-based extrinsic Fabry-Perot interferometric optical fiber pressure sensor [7656-174]

Q. Wang, Dalian Univ. of Technology (China); W. Wang, Dalian Univ. of Technology (China) and Guangdong Ocean Univ. (China); X. Jiang, Fujian Castech Crystals, Inc. (China); Q. YU, Dalian Univ. of Technology (China)

7656 4W Combination of skip-flat test with Ritchey-Common test for the large rectangular flat [7656-175]

L. Zhang, B. Xuan, Changchun Institute of Optics, Fine Mechanics and Physics (China) and Graduate School of Chinese Academy of Sciences (China); J. Xie, Changchun Institute of Optics, Fine Mechanics and Physics (China) 
7656 4X Analysis of the effects on ultra-short laser pulse beam quality caused by errors in optical systems [7656-176]

H. Shang, Z. Cen, X. Li, Q. Liu, W. Hu, Zhejiang Univ. (China)

$76564 \mathrm{Y}$ Testing aspheric surface with annular subaperture stitching method based on Hartmann Shack sensor [7656-177]

H. Xu, Institute of Optics and Electronics (China), The Key Lab. on Adaptive Optics (China), and Graduate School of the Chinese Academy of Sciences (China); H. Xian,

Y. Zhang, Institute of Optics and Electronics (China) and The Key Lab. on Adaptive Optics (China)

$76564 Z$ Study on energy control system of film damage threshold testing by LabVIEW [7656-178] J. Su, C. Cheng, J. Xu, L. Yang, B. Liu, Xi'an Technological Univ. (China)

765650 Axial super-resolution of Gaussian beam by pupil filters [7656-179] X. Zhao, Xi'an Research Institute of High-Technology (China); S. Wang, Tianjin Polytechnic Univ. (China); Z. Zhang, C. Liu, Xi'an Research Institute of High-Technology (China)

$765651 \quad$ Misalignment model used in three-position absolute measurement [7656-180] P. Yang, Institute of Optics and Electronics (China) and Graduate School of Chinese Academy of Sciences (China); F. Wu, Institute of Optics and Electronics (China); X. Hou, Graduate School of Chinese Academy of Sciences (China)

765652 Study on camouflage effect of targets with different characteristics under typical background [7656-181]

S. Gao, W. Jin, J. Wang, H. Wang, H. Li, A. Guo, Beijing Institute of Technology (China)

765653 Application of digital holography in temperature distribution measurement [7656-182] Y. Wang, D. Wang, Y. Li, J. Zhao, P. Meng, Y. Wan, Z. Jiang, Beijing Univ. of Technology (China)

765654 Design of miniature hybrid target recognition system with combination of FPGA+DSP [7656-183]

S. Luo, X. Li, H. Jia, W. Hu, Y. Nie, S. Chang, National Univ. of Defense Technology (China)

$765655 \quad$ Novel gas sensor used for $\mathrm{C}_{2} \mathrm{H}_{2}$ trace detection in power transformer [7656-184] Z. Ding, J. Bao, Ningbo Univ. of Technology (China); X. Fang, Ningbo Univ. of Technology (China) and Gannan Normal Univ. (China); H. Zhao, H. Ja, Ningbo Univ. of Technology (China)

765656 Non-contact high precision measurement of surface form tolerances and central thickness for optical elements [7656-185]

Y. Lou, China North Optical-electrical Technology Co., Ltd. (China)

765657 Three-position method for leveling optical surface automatically based on 2D PSD [7656-186]

Z. Wei, K. Yang, X. Long, National Univ. of Defense Technology (China) 
765658 Study on influencing factors of measuring precision of OTF measurement instrument [7656-187]

K. Zhao, J. Meng, Z. Zhang, Y. Tao, C. Zhang, L. Lei, X. Dun, L. Feng, Tianjin Jinhang Institute of Technical Physics (China)

765659 CCD non-uniformity effects on position accuracy of star sensor [7656-188]

J. Liao, H. Liu, H. Jia, National Univ. of Defense Technology (China); J. Yang, National Univ. of Defense Technology (China) and National Lab. of Space Intelligent Control (China);

J. Tan, National Univ. of Defense Technology (China)

7656 5A Beam wavefront and farfield control for ICF laser driver [7656-189]

W. Dai, W. Deng, X. Zhang, X. Jiang, K. Zhang, W. Zhou, J. Zhao, D. Hu, CAEP (China)

7656 5B Phase-stepping method for whole-field photoelastic stress analysis using plane polariscope setup [7656-190]

X. Zhang, L. Chen, C. He, Beijing Institute of Technology (China)

7656 5C Study on ultra-fast single photon counting spectrometer based on $\mathrm{PCl}$ [7656-191]

$X$. Zhang, Dalian Nationalities Univ. (China)

7656 5D Fiber methane gas detector based on harmonic detection and application in ventilation air methane power generation [7656-192]

Y. Li, Y. Wei, Y. Shang, Y. Zhao, T. Zhang, W. Zhao, C. Wang, T. Liu, Shandong Academy of Science (China)

$76565 \mathrm{E}$ Strain-temperature monitor of high speed railway switch by fiber Bragg grating gauges [7656-193]

W. Li, X. Huang, J. Cheng, J. Pan, Wuhan Univ. of Technology (China)

$76565 \mathrm{~F}$ Direct absorption measurement of ambient nitric oxide based on room-temperature pulsed quantum cascade laser [7656-194]

Y.-Y. Tang, W.-Q. Liu, R.-F. Kan, Y.-J. Zhang, Y.-B. Cui, Z.-Y. XU, Anhui Institute of Optics and Fine Mechanics (China)

7656 5G Determination of the optical constants of thin films by means of transmission spectra and curve fitting [7656-195]

H. Jia, H. LU, J. Peng, Univ. of Shanghai for Science and Technology (China)

$76565 \mathrm{H} \quad$ Feedback compensation method for angular displacement measurement based on a Fabry-Perot interferometer [7656-196]

C. Zhang, X. Zhang, Zhejiang Univ. (China)

765651 Modulation transfer function measurement of sampled imaging systems in field test [7656-197]

L. Yang, Changchun Institute of Optics, Fine Mechanics and Physics (China) and Graduate School of Chinese Academy of Sciences (China); Q. Sun, J. Wang, Changchun Institute of Optics, Fine Mechanics and Physics (China); J. Zhang, Changchun Institute of Optics, Fine Mechanics and Physics (China) and Graduate School of Chinese Academy of Sciences (China) 
7656 5J Measurement and analysis of surface profiles by inverse scattering method [7656-198] S. Chen, X. XU, L. Qi, Harbin Engineering Univ. (China)

7656 5K Analysis of closed fringe patterns for aspheric surface measurement [7656-199] L. Nie, B. Liu, J. Han, X. Yu, Xi'an Technological Univ. (China)

$76565 \mathrm{~L} \quad$ Research on the application of lidar extinction coefficient inversion method [7656-200] P. Liu, H. Chen, Y. Zhang, S. Chen, Z. Qiu, Y. Wang, W. Kong, G. Ni, Beijing Institute of Technology (China)

$76565 \mathrm{M}$ Photogrammetry research for FAST eleven-meter reflector panel surface shape measurement [7656-201]

R. Zhou, L. Zhu, National Astronomical Observatories (China); W. Li, Univ. of Science and Technology of China (China); J. Hu, X. Zhai, National Astronomical Observatories (China)

$76565 \mathrm{~N} \quad$ Fiber optic TDLAS-based multi-gas remote detection system for mine goaf fire [7656-202] Y. Wei, Y. Li, Y. Shang, T. Zhang, Z. Song, C. Wang, T. Liu, Shandong Academy of Sciences (China)

765650 Study on laser Raman spectrum with different excitation wavelength [7656-203] H. Liang, Hebei Univ. of Engineering (China); J. Wang, Sichuan Univ. (China); X. Wang, H. Cheng, Hebei Univ. of Engineering (China)

7656 5P Digital speckle correlation method based on wavelet transform using micro-displacement measurement [7656-204]

X. Li, Z. Zhen, Q. Chen, L. Li, Henan Univ. of Science and Technology (China)

$76565 \mathrm{Q}$ Velocity measurement by speckle modulating an Erbium-doped fiber ring laser [7656-205] D. Han, S. Chen, Nanchang Univ. (China); D. Guo, Nanjing Normal Univ. (China)

$76565 R$ Straight interference fringes thinning algorithm [7656-206]

Z. Ren, Z. Fan, P. Ran, J. Li, Kunming Univ. of Science and Technology (China)

765655 Measurement of a turbid medium's refractive index with optical coherence tomography [7656-207]

Y. Feng, Beijing Institute of Petrochemical Technology (China); Y. Liu, Beijing Institute of Petrochemical Technology (China) and Beijing Univ. of Chemical Technology (China)

$76565 \mathrm{~T} \quad$ High-precision digital synchronous system in the physical diagnosis of multi-beam laser target system [7656-208]

Y. Xue, Xi'an Institute of Optics and Precision Mechanics (China) and Graduate School of the Chinese Academy of Sciences (China); Y. Bai, B. Liu, B. Wang, Xi'an Institute of Optics and Precision Mechanics (China); Y. Li, Xi'an Institute of Optics and Precision Mechanics (China) and Graduate School of the Chinese Academy of Sciences (China); X. Ouyang, Xi'an Institute of Optics and Precision Mechanics (China); Y. Gou, W. Zhang, Xi'an Institute of Optics and Precision Mechanics (China) and Graduate School of the Chinese Academy of Sciences (China)

$76565 \mathrm{U}$ Design and research of analysis instrument based on Q-switch micro-crystal UV Laser-induced Fluorescence Spectroscopy [7656-209]

S. Yu, H. Han, J. YU, Y. Fu, P. Sha, Donghua Univ. (China) 
$76565 \mathrm{~V}$ Mechanical characteristics of glass-ceramics surface by means of nano-indentation [7656-210]

J. Wang, X. Wang, Harbin Institute of Technology (China); X. Song, S. Li, Flight Automatic Control Research Institute (China); J. Chen, Harbin Institute of Technology (China)

7656 5W Measurement of beam waist of the long focal laser system [7656-211]

H. Fan, Southwest Institute of Technical Physics (China); H. Zhang, Q. Zhao, Sichuan Univ. (China); M. Dai, Southwest Institute of Technical Physics (China)

$76565 \mathrm{X}$ New phase measurement method for laser rangefinder [7656-212] W. Sun, J. Sun, W. Bu, Harbin Normal Univ. (China); Z. Meng, Changchun Institute of Optics, Fine Mechanics and Physics (China)

$76565 Y$ Diffraction wavefront analysis of point diffraction interferometer for measurement of aspherical surface [7656-213]

F. Gao, Xi'an Jiaotong Univ. (China) and Xi'an Technological Univ. (China); Z. Jiang, B. Li, Xi'an Jiaotong Univ. (China)

$76565 Z$ Effect of optical aberration of telescopes to the laser radar [7656-214] Q. Zhao, Sichuan Univ. (China); H. Fan, S. Hu, M. Zhong, Southwest Institute of Technical Physics (China); L. Baida, Sichuan Univ. (China)

765660 Study on the relationship between deflection angle and scanning angular of optical scanner [7656-215]

G. Sun, Q. Mi, Xi'an Technological Univ. (China)

765661 Test of film thickness based on annular sub-aperture stitching interference [7656-216] L. Yang, Xi'an Technological Univ. (China) and Xi'an Univ. of Technology (China); J. Su, Z. Chen, Xi'an Technological Univ. (China)

765662 Alignment and arm length measurement of the swing arm profilometer using a laser tracker [7656-217]

H. Jing, Institute of Optics and Electronics (China); C. King, D. Walker, Univ. College London (United Kingdom)

765663 Point detection and positioning system of the target based on surface cluster eyes [7656-218]

F. Guo, H. Zhang, K. Wang, Univ. of Science and Technology of China (China)

765664 Novel refractometer based on a phase-shift-adjustable fiber Bragg grating [7656-219]

W. Zhou, X. Dong, C.-L. Zhao, L. Li, C. Shen, S. Jin, China Jiliang Univ. (China)

765665 Research on the precision measurement of super-low reflectivity [7656-220] H. Yuan, Z. LU, Y. Xia, Z. Peng, H. Liu, L. Xu, Z. Sun, J. Tang, Chinese Academy of Engineering Physics (China)

765666 Investigation on metal stress corrosion monitoring by laser speckle interferometry device [7656-221]

J. LU, G. P. Zou, Harbin Engineering Univ. (China) 
765667 Analysis and discussion on the control system of human eye aberration measurement unit based on information fusion technology [7656-222]

J. Zhao, A. Xu, X. Pan, Changzhou Institute of Technology (China)

765668 Compound interferometer system for large-scale optical components surface measurement [7656-223]

Q. Wang, T. Sun, C. Han, S. Dong, Harbin Institute of Technology (China); A. Yu. Rodionov, A. S. Shirin, V. N. Shekhtman, EFL LTD (Russian Federation)

765669 Measurement method of multi-degree-freedom based on laser collimation principle [7656-224]

L. Yang, Hubei Univ. of Technology (China) and Guangxi Key Lab. of Manufacturing System and Advanced Manufacturing Technology (China); X. Wang, L. Long, Hubei Univ. of Technology (China)

7656 6A Numerical simulation for effects of high-power laser propagation in atmosphere over land [7656-225]

C. Yang, Y. Zhang, M. Kang, J. Guo, J. Wu, Univ. of Electronic Science and Technology of China (China)

7656 6B Evaluate the task-specific measurement uncertainty of laser tracker using Monte-Carlo method [7656-226]

J. Li, S. Wu, F. Wu, L. Kuang, X. Cao, Institute of Optics and Electronics (China) and Graduate School of the Chinese Academy of Sciences (China)

7656 6C Improved zone-plate interferometer for measuring aspheric surface [7656-227] L. Nie, G. Wang, G. Quan, Xi'an Technological Univ. (China)

7656 6D Method based on video imaging to correct the consistency of multi-optical axes [7656-228] N. Wang, Y. Li, J. Fan, Y. Jiang, F. Fan, W. Jin, X. Wang, Beijing Institute of Technology (China)

7656 6E Quantitative detection of defect using ultrasound infrared lock-in thermography [7656-229] H. Liu, J. Liu, Y. Wang, Harbin Institute of Technology (China)

7656 6F Sidelobe reduction of acousto-optic tunable filter by double-filtering [7656-230] C. Zhang, H. Wang, Y. Qiu, Fujian Normal Univ. (China)

7656 6G Research on automatic Hartmann test of membrane mirror [7656-231]

X. Zhong, G. Jin, Changchun Institute of Optics, Fine Mechanics and Physics (China); C. Liu, P. Zhang, Changchun Institute of Optics, Fine Mechanics and Physics (China) and Graduate School of the Chinese Academy of Sciences (China)

$76566 \mathrm{H}$ Considerations on testing of CFGT primary segments [7656-232]

L. Jiang, Nanjing Institute of Astronomical Optics \& Technology, National Astronomical Observatories (China) and Graduate Univ. of Chinese Academy of Sciences (China); X. Li, Nanjing Institute of Astronomical Optics \& Technology and National Astronomical Observatories (China)

765661 Method to detect and calculate motion blur kernel [7656-233] J. Wu, H. Feng, Z. XU, Q. Li, Z. Fu, Zhejiang Univ. (China) 
7656 6J Auto-measurement system of aerial camera lens' resolution based on orthogonal linear CCD [7656-234]

Y. Zhao, Y. Zhang, H. Ding, Navy Aeronautical and Astronautical Univ. (China)

7656 6K Defocusing compensation system of long focal aerial camera based on auto-collimation [7656-235]

Y. Zhang, Y. Zhao, Z. XU, Navy Aeronautical and Astronautical Univ. (China)

$76566 \mathrm{~L}$ Satellite APT system for Satellite-earth laser communication modeling, simulation and analysis [7656-236]

K. Ding, Institute of Optics and Electronics (China), The Key Lab. of Beam Control (China), and Graduate Univ. of Chinese Academy of Sciences (China); Y. Huang, J. Ma, Institute of Optics and Electronics (China) and The Key Lab. of Beam Control (China)

7656 6M Study on computer-aided alignment method of a three-mirror off-axis aspherical optical system [7656-237]

X. Zhao, W. Jiao, Z. Liao, Y. Wang, J. Chen, Beijing Institute of Space Mechanics \& Electricity (China)

7656 6N Application research on asynchronous vibration measurement of rotating blades based on optical-fiber sensor [7656-238]

Y. Zhang, Beijing Institute of Space Mechanics \& Electricity (China); F. Duan, State Key Lab. of Precision Measuring Technology and Instruments (China); T. Li, Beijing Institute of Space Mechanics \& Electricity (China); M. Li, T. Ouyang, State Key Lab. of Precision Measuring Technology and Instruments (China)

765660 Evaluation of anti-vibration capability of the wavefront testing method in time- and spatial-domain [7656-239]

L. Tang, Beijing Research Institute of Special Mechanical and Electric Technology (China) and Beijing Institute of Technology (China); Q. Hao, Q. Zhu, Beijing Institute of Technology (China); J. Wang, Beijing Research Institute of Special Mechanical and Electric Technology (China); C. Zhang, Beijing Research Institute of Special Mechanical and Electric Technology (China), Beijing Institute of Technology (China), and Airforce Radar Academy (China)

7656 6P Study on spectrometer based upon volume holographic transmission grating [7656-240] Z. Huang, G. Liu, Z. Ren, L. Zeng, Jiangxi Science and Technology Normal Univ. (China)

$76566 \mathrm{Q}$ Study on attenuation performance of water fog to $10.6 \mu \mathrm{m}$ laser emission by laser granularity analyzer and transmitter [7656-241]

$X$. Wang, T. Fu, Y. Zhao, Institute of Chemical Defense (China)

7656 6R Disposition of camera parameters in vehicle navigation system [7656-242]

H. YU, Southeast Univ. (China) and Nanjing Univ. of Aeronautics \& Astronautics (China); W. Zhang, Southeast Univ. (China)

7656 6S Optical correlator based system for displacement auto detection [7656-243]

C. Dai, P. Ge, Q. Li, H. Feng, Z. Xu, Zhejiang Univ. (China)

$76566 \mathrm{~T}$ Determination the optical constants of hafnium oxide film by Spectroscopic ellipsometry with various dispersion models [7656-244]

W. Gao, Y. Zhang, H. Liu, Institute of Optics and Fine Mechanics (China) 
$76566 \mathrm{U}$ Research of fluorescence lifetime imaging technology based on heterodyne method of frequency domain [7656-245]

C. Sheng, T. Li, H. Tang, Shandong Univ. of Technology (China)

7656 6V Establishment and study on dihedral angle detection model of retro-reflector based on Zygo interferometer [7656-246]

X. Feng, W. Zhong, G. Wu, H. Zhou, Wuhan Univ. (China)

7656 6W Optimal waveband and mathematical model for analysis of human whole blood glucose by near infrared transmission spectroscopy [7656-247]

F. Huang, J. Yu, S. Li, D. Wang, Y. Luo, Jinan Univ. (China); S. Zheng, The First Affiliated Hospital Jinan Univ. (China)

7656 6X Improving the optimization efficiency and precision of least squares support vector regression (LSSVR) for pear property prediction [7656-248]

Y. Hao, Y. Liu, H. Zhang, X. Liu, Y. Pan, East China Jiaotong Univ. (China)

$76566 \mathrm{Y}$ Key technology of data registration for large aperture aspheric surface measurement [7656-249]

T. Ren, Y. Guo, X. Ke, Xiamen Univ. (China)

$76566 Z$ Method for measuring profile of large aspheric optics at grinding stage based on NC machine [7656-250]

Y. Zhang, Institute of Optics and Electronics (China) and Graduate School of Chinese Academy of Sciences (China); F. Bin, J. B. Zhou, Graduate School of Chinese Academy of Sciences (China)

765670 Study on a novel algorism of phase unwrapping for interferogram processing [7656-251] J. Su, W. Wan, L. Yang, J. Xu, Xi'an Technological Univ. (China)

765671 Research on active suppression resonant peak of pneumatic vibration isolators at optical instrument platform [7656-252]

J. He, T. Liu, Univ. of Shanghai for Science and Technology (China)

765672 Design of a portable microfiber optic spectrometer [7656-253]

J. Tong, Y. Yang, C. Sui, D. Xu, F. Wang, Zhejiang Univ, of Technology (China)

765673 Research on third-order susceptibility tensor of silicon at telecom wavelength [7656-254] Y.-H. Zhang, H. Liu, Jilin Architectural and Civil Engineering Institute (China); Z.-G. Chen, G. Jia, C. Ren, Jilin Univ. (China)

$765674 \quad$ Novel auto-focusing method [7656-255]

Y. Huang, D. Ye, R. Che, Harbin Institute of Technology (China)

765675 Calibration error of Hartmann wavefront sensor caused by nonuniform intensity distribution [7656-256]

J. Huang, Institute of Optics and Electronics (China), The Key Lab. on Adaptive Optics

(China), and Graduate School of Chinese Academy of Sciences (China); H. Xian, Institute of Optics and Electronics (China) and The Key Lab. on Adaptive Optics (China) 
765676 Online detecting system of roller wear based on laser-linear array CCD technology [7656-257]

Y. Guo, Qi Qihaer Univ. (China)

765677 FPGA and DSP based an intelligent visual sensor design for laser welding seam recognition [7656-258]

F. Jiang, Liaoning Shihua Univ. (China); C. Jiang, Shenyang Institute of Automation (China);

H. Ge, Liaoning Shihua Univ. (China)

765678 Research on ship wake detection mechanism based on optical backscattering effect [7656-259]

D. Zhu, X. Zhang, J. Rao, Naval Univ. of Engineering (China); S. Jin, Units 91550, Navy (China);

K. Liu, Naval Univ. of Engineering (China)

765679 Research of laser ignition detection system [7656-260]

F. Yang, D. Zhao, Q. Xu, X. Ai, Fudan Univ. (China)

$76567 \mathrm{~A} \quad$ Multiple disturbance location in distributed fiber-optic sensor based on phase generated carrier [7656-261]

H. Xu, Y. Zhang, H. Wu, Q. Xu, Q. Xiao, Fudan Univ. (China)

$76567 B \quad$ Study on dynamic imaging on TDI CCD optical remote sensor of push-broom technology [7656-262]

M. Gao, G. Zhao, L. Liu, J. Ren, Changchun Institute of Optics, Fine Mechanics and Physics (China)

$76567 \mathrm{C}$ Laser ranging based on secondary modulated beam [7656-263]

D. Zhao, Y. Feng, H. Tang, Fudan Univ. (China)

7656 7D Flexible coordinate measurement system based on robot for industries [7656-264]

Y. Guo, X. Yang, C. Liu, S. Ye, Tianjin Univ. (China)

$76567 \mathrm{~N} \quad$ Novel design method for pulse laser reception circuit based on PIN [7656-265]

T. Zhang, B. Wu, C. Liu, Tianjin Univ. (China)

$76567 F \quad$ Research on distributed fiber-optic sensor based motor fault monitoring system [7656-266]

Y. Zhang, H. XU, Q. Xiao, H. Wu, D. Zhao, Fudan Univ. (China)

$76567 G$ Study on the structure of CGH with same diffraction efficiency of 0-order and 1-order [7656-267]

J. Ren, P. Guo, Suzhou Univ. (China); B. Zhang, Changchun Univ. of Science and Technology (China)

$76567 \mathrm{H}$ Development of automatic dual-channel SPR detecting instrument [7656-268]

Q. Li, S. Zhan, B. Sun, X. Wang, Zhejiang Univ. (China)

7656 7I A circular micro-grating array for Shack Hartmann wavefront sensors [7656-269]

H. Wang, L. Wei, J. Chen, Institute of Optics and Electronics (China)

7656 7J IR null correctors for ground aspheric surface [7656-270]

Y. Wu, Y. Zhang, Institute of Optics and Electronics (China) 
$76567 \mathrm{~L} \quad$ Noise filtering for MoiréFringe signals based on variable step size adaptive neural network algorithm [7656-271]

M. Lv, Q. Guo, C. Zhang, Y. Meng, First Aeronautical College of AF (China)

Author Index

xxvi

Downloaded From: https://www.spiedigitallibrary.org/conference-proceedings-of-spie on 25 Apr 2023 Terms of Use: https://www.spiedigitallibrary.org/terms-of-use 


\title{
Symposium Committees
}

\author{
Honorary Chair
}

Daheng Wang, Chinese Academy of Sciences (China) and Chinese Academy of Engineering (China)

Symposium General Chair

Bingkun Zhou, Chinese Optical Society (China) and Chinese Academy of Sciences (China)

Symposium General Cochairs

Jianlin Cao, Ministry of Science and Technology of China (China)

James C. Wyant, College of Optical Sciences, The University of Arizona (United States)

Yudong Zhang, Institute of Optics and Electronics, CAS (China)

Michael Pfeffer, German Institute of Applied Optics (Germany)

Peigeng Li, Huazhong University of Science \& Technology (China) and Chinese Academy of Engineering (China)

Guofan Jing, Tsinghua University (China) and Chinese Academy of Engineering (China)

Chunhao Zhang, China Association for Science (China), Chinese Academy of Sciences (China), and Dalian Institute of Chemical Physics (China)

International Academic Committee

Wenhan Jiang, Chair, Chinese Academy of Engineering (China) and Institute of Optics and Electronics, CAS (China)

Fengting Sang, Chinese Academy of Engineering (China) and Dalian Institute of Chemical Physics, CAS (China)

Lishi Wen, Chinese Academy of Engineering (China) and Dalian University of Technology (China)

Guoguang Mu, Chinese Academy of Sciences (China) and Nankai University (China)

Yijun Zhao, Chinese Academy of Engineering (China) and National University of Defense Technology (China)

Xingdan Chen, Chinese Academy of Engineering (China) and Changchun Institute of Optics, Fine Mechanics and Physics, CAS (China)

Dianyuan Fan, Chinese Academy of Engineering (China) and Shanghai Institute of Optics and Fine Mechanics, CAS (China)

Liding Wang, Chinese Academy of Sciences (China) and Dalian University of Technology (China) 
Junhua Pan, Chinese Academy of Engineering (China) and Soochow University (China)

Junhao Chu, Chinese Academy of Sciences (China) and Shanghai Institute of Technical Physics, CAS (China)

Liwei Zhou, Chinese Academy of Engineering (China) and Beijing Institute of Technology (China)

Roland Geyl, Sagem SA (France)

Jose M. Sasian, College of Optical Sciences, The University of Arizona (United States)

Fritz Klocke, Fraunhofer Institute for Production Technology IPT (Germany)

James R. Torley, University of Colorado at Colorado Springs (United States)

Yoshiharu Namba, Chubu University (Japan)

James H. Burge, College of Optical Sciences, The University of Arizona (United States)

David D. Walker, University College London (United Kingdom)

\section{Organizing Committee}

Yudong Zhang, Chair, Institute of Optics and Electronics, CAS (China)

Jinghua Cao, Cochair, Chinese Academy of Sciences (China)

Libin Xiang, Cochair, Academy of Optoelectronics, CAS (China)

Anand Asundi, Cochair, Nanyang Technological University (Singapore)

Guoqiang Ni, Cochair, Chinese Optical Society (China)

Program Committee

Xiangdi Lin, Chair, Chinese Academy of Engineering (China)

Hu Yang, Cochair, Institute of Optics and Electronics, CAS (China)

Yuwen Qing, Cochair, Natural Science Foundation of China (China)

Haodong Yu, Cochair, Changchun University of Science and Technology (China)

Sen Han, Cochair, Veeco Instruments Inc. (United States)

Myung K. Cho, Cochair, National Optical Astronomy Observatory (United States)

Secretary General of the Symposium

Li Yang, Committee of Optical Manufacturing Technology, COS (China) Jinxue Wang, SPIE 


\title{
Conference Committee
}

\author{
Conference Chairs \\ Yudong Zhang, Institute of Optics and Electronics, CAS (China) \\ Jose M. Sasian, College of Optical Sciences, The University of Arizona \\ (United States) \\ Libin Xiang, Academy of Opto-Electronics, CAS (China) \\ Sandy To, The Hong Kong Polytechnic University (Hong Kong, China) \\ Session Chairs \\ 1 Session 3-1 \\ Shibin Wu, Institute of Optics and Electronics, CAS (China) \\ 2 Session 3-2 \\ Shengyi Li, National University of Defense Technology (China) \\ 3 Session 3-3 \\ Hongwei Jing, Institute of Optics and Electronics, CAS (China)
}


Downloaded From: https://www.spiedigitallibrary.org/conference-proceedings-of-spie on 25 Apr 2023

Terms of Use: https://www.spiedigitallibrary.org/terms-of-use 


\section{Introduction}

The 5th International Symposium on Advanced Optical Manufacturing and Testing technologies (AOMATT) was held 26-29 April 2010 at Dalian World Expo Center in the beautiful city of Dalian, China. This is the same venue where the 2007 World Economy Forum of DAVOS was held. AOMATT was initiated in 2000 to provide a forum for international researchers, designers, managers, and manufacturers to discuss related technologies in this area. The first meeting, AOMATT 2000, was held in Chengdu, China. Since then, AOMATT has increasingly become a must-attend conference for the international optical design, manufacturing, and testing communities. AOMATT has developed a reputation for excellent plenary sessions, quality oral and poster papers, and fun social events.

AOMATT 2010 was opened with a grand opening ceremony and outstanding plenary sessions. About 1,000 delegates attended the opening ceremony and plenary sessions in the multi-functional hall of the Dalian World Expo Center. Honored guests and sponsoring and cooperating organization representatives, including Professor Qing Yu Weng representing the National Science Foundation of China (NSFC), Dr. Jinxue Wang representing SPIE, technical cosponsor of AOMATT, and Dr. James C. Wyant, Dean of Optical Sciences at the University of Arizona and 2010 president of OSA, gave welcome and congratulation speeches at the opening ceremony. Professor Guofan Jin, an academician of the Chinese Academy of Engineering and cochair of the symposium, gave an opening speech in written form on behalf of the Chinese Optical Society (COS). Plenary speakers included Dr. Roland Geyl from REOSC of France, Dr. Hong Minghui from the National University of Singapore, Dr. Yoshiharu Namba from Chubu University of Japan, Dr. James Wyant from the University of Arizona in the USA, Dr. Thomas Franz from the NTG Company in Germany, Professor Fengting Sang, an academician from the Dalian Institute of Chemical Physics, Chinese Academy of Sciences (CAS), and Professor Xiangqun Cui, an academician from the Nanjing Institute of Astronomical Optics and Technology, National Astronomical Observatory, CAS. Other academicians attending AOMATT 2010 included: Wenhan Jiang from IOE of CAS, Can Li from DICP of CAS, Junhua Pan from Suzhou University, Liwei Zhou from Beijing Institute of Technology, and Yijun Zhao from the National University of Defense Technology.

AOMATT 2010 received more than 1,300 abstracts. After careful reviews by the conference chairs and committee members and an invited reviewer, more than 700 papers were accepted for presentation at the conference and publication in the Proceedings of SPIE. The AOMATT 2010 proceedings are divided into six volumes - 7654-7659 - and correspond to the six conferences of the symposium, namely, Large Mirrors and Telescopes; Advanced Optical Manufacturing Technologies; Optical Test and Measurement Technology and Equipment; 
Design, Manufacturing, and Testing of Micro- and Nano-Optical Devices and Systems; Optical Materials, Detectors, Imagers, and Energy Conversion Technology; and Smart Structures and Materials in Manufacturing and Testing.

There is continued improvement in paper quality compared to previous AOMATT symposiums. Many papers report cutting-edge research and development. More authors are from well-known universities, research institutions, and corporations around the world. We believe AOMATT 2010 made another important step in establishing itself as an essential international symposium for the international optical design, manufacturing, and testing communities.

We would like to express our sincere appreciation to COS-The Chinese Optical Society, IOE-Institute of Optics and Electronics, the Chinese Academy of Sciences, and to SPIE for supporting AOMATT. We want to thank all the authors and participants for attending the symposium and sharing their research with colleagues around the world. We especially thank IOE and Dr. Yudong Zhang, President of IOE, for their steadfast support of AOMATT since its inception in 2000.

We look forward to your participation and support of the 6th AOMATT in 2012. Location, time, and the call for papers will be posted on SPIE and IOE websites soon. 